\title{
A Pseudo-Comprehensive LCA Carbon Footprint Model for Fossil Fuel Power Plants (an Iranian Case)
}

\author{
Fatemeh Dalir, Majid Shafiepour Motlagh*, Khosro Ashrafi \\ University of Tehran, Ghods St., Enghelab Ave, Tehran, Iran
}

Received: 23 December 2016

Accepted: 16 January 2017

\begin{abstract}
This paper presents an LCA model to estimate the carbon footprint of a fossil fuel power plant for better policy implementation in an energy portfolio. The frameworks of the proposed model have integrated two groups of parameters (parameters affecting emissions and parameters affecting the amount of electricity) into one model. The model is developed to handle three types of power plants: gas turbine, combined cycle, and steam power with different fuel types and different utility transfer policies. The model is verified with two case studies in Iran. The results show good agreement between the model output and existing conditions.
\end{abstract}

Keywords: carbon footprint, power plant, electricity transmission and distribution

\section{Introduction}

In the year 2013 International Energy Agency has been announced that around 25,000 TWh of electricity have been produced in the world and approximately 13.5 Gt $\mathrm{CO}_{2}$ eq (equivalent) has been emitted consequently [1]. Many researchers have worked on assessing GHG emissions for different electricity generation technologies. Most of them have studied the life cycle environmental impacts of electricity generation on a national scale. Among them are Borizmohun et al. (2015), Treyer and Bauer (2016), Višković and Franki (2015), Atilgan and Azpagic (2015), and Georgakellos (2012) and Bozic et al. (2013), who have worked on a national scale for Turkey, Mauritius, Greece, Croatia, UAE, and Serbia [27]. However, they have assessed the GHGs (greenhouse gases) under environmental impact for existing conditions, and no one has proposing a model that can be applied not only for the existing conditions but also for use in a feasibility study to determine emissions for future power plant construction. This paper proposes a pseudo comprehensive well-to-wire carbon footprint model for fossil fuel power plants. In contrast to the previous studies that have addressed only total emissions and net electrical energy, this paper calculates the carbon footprint of the power plant considering nine parameters: plant type, fuel type, fuel transmission type, emission for fuel extraction and processing, consumption of the plant, degradation, site ambient condition, transmission, and distribution losses. Considering that the effect of degradation and its own consumption are the distinguishing features of the proposed model, to verify the accuracy of the proposed model it has been compared to the existing conditions of power plants in the Iranian electrical energy network.

*e-mail: Shafiepourm@yahoo.com 


\section{Material and Methods}

To propose the model, the framework of the life cycle assessment (LCA) approach has been used to estimate carbon footprint of the power sector following the LCA methodology described in ISO 14067 [8], which also includes precise calculations of $\mathrm{CH}_{4}$ and $\mathrm{N}_{2} \mathrm{O}$ emissions. The emissions are converted to carbon dioxide equivalents based on the 100-year global warming potential factors reported by the IPCC's Fifth Assessment Report 2014 [9]. Carbon footprint is the science of calculating the amount of $\mathrm{CO}_{2}$ eq emitted during the producing phases of a unit of product. Therefore, Eq. (1) is considered for calculation of carbon footprint of power plants:

$$
\text { Carbon Footprint }(\mathrm{CF})=\frac{\text { total equivalent } \mathrm{CO}_{2} \text { emission }}{\text { ṔOH }}
$$

...where $P$ is the modified power of the plant (the net capacity of the plant) and $\mathrm{OH}$ is the operating hours in an arbitrary time span. Considering the operational concept of power plants, the parameters actually touch either the emission or net produced energy. Plant type, fuel type, fuel transfer emission, fuel preparation emission (extracting and processing), influence of the emission and its own consumption, degradation, ambient condition, transmission, and distribution losses affect net electrical energy delivered to the consumers. Fig. 1 shows a block diagram of the calculation process and presented graphical state of emission and electrical losses. The losses would be further continuing in other LCA phases of the product, which mainly contribute to transmission and distribution.

Emission of the plant in all phases of its life has three components that directly and indirectly are connected to the plant's operation. These components are expressed in Eq. (2):

$$
t c=e f+e c+e t
$$

...where $t c$ is total emission in $\mathrm{kg}$, ef is fuel preparation emissions in $\mathrm{kg}$ (fuel preparation emissions is a term of emission from the extraction well and processing of the fuel), $e c$ shows fuel combustion emission in $\mathrm{kg}$, and et indicates fuel transfer emission in $\mathrm{kg}$.

Emission of fuel combustion depends on the amount and type of fuel consumed. Actually, the heat content of the fuel and consequently the emission factors play

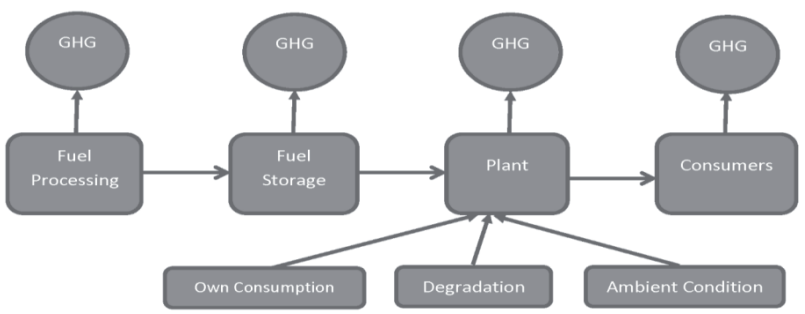

Fig. 1. Block diagram of the process. an essential role in final calculation. Eq. (3) shows the combustion emission of a mixture of natural gas (NG), diesel oil (DO), and residual oil (RO):

$$
e c=\sum_{i} a_{i} e f_{i} V_{i}
$$

...in which $\alpha_{i}$ and ef are calculated by Eqs. (4) and (5):

$$
\begin{gathered}
\alpha_{i}=10^{-9} \rho_{i} L H V_{i} \\
e f_{i}=e f_{\mathrm{CO}_{2} i}+21 e f_{\mathrm{CH}_{4} i}+276 e f_{\mathrm{N}_{2} \mathrm{O} i}
\end{gathered}
$$

...where $i$ stands for fuel type index and switches to NG, $\mathrm{DO}, \mathrm{RO} ; e c$ indicates emission of combustion in $\mathrm{kg} ; \rho$ is density of fuel in $\mathrm{kg} / \mathrm{m}^{3} ; L H V$ shows low heating value in $\mathrm{kJ} / \mathrm{kg} ; V$ is volume of fuel consumed in $\mathrm{m}^{3}$; and ef presents emission factor in $\mathrm{kg} / \mathrm{TJ}$. Emission factors for combustion of the mention fuels are excerpted from IPCC Guidelines for National Greenhouse Gas Inventories [10]. If the amount of fuel cannot be derived directly from statistics, it can be derived from heat rate of the plant or directly from design criteria documents of the plant. The procedure is defined stepwise below [11]:

$$
T H R=H R \cdot G P P
$$

...where $T H R$ stands for the total heat required, $H R$ is heat rate of the plant, and GPP represent gross plant production.

$$
V_{i}=\frac{T H R / \rho_{i}}{L H V_{i}}
$$

Fuel transfer is also a cause of indirect emissions. Fuels are transferred to the plant via pipeline, rail, and road trucks. Natural gas is always transmitted via pipeline in Iran. Diesel oil and residual oil are sometimes transmitted via pipeline, like for the Shazand and Sahand Power Plant. If fuels are transmitted by pipeline, the emission is estimated by Eq. (8).

$$
\text { et }=\sum_{i} 10^{-12} V_{i} e f_{i}
$$

...where $i$ is fuel type index and switches to NG, DO, $\mathrm{RO}$; et presents emission of fuel transfer in $\mathrm{kg} ; \mathrm{V}$ shows volume of fuel consumed in $\mathrm{m}^{3}$; and ef indicates emission factor in $\mathrm{Gg} / 10^{6} \mathrm{~m}^{3}$. If the liquid fuels are transmitted to the power plant via road or rail freight transit, the decisive parameters are the distance of fuel transfer and vehicle fuel consumption. The mentioned parameters are formulated to estimate the emissions in Eq. (9) [12]:

$$
e t=\sum_{i, j} f c_{j .} d_{i j}\left(v_{i} p_{i}\right) \beta_{i} e f
$$

And $\beta$ and $e f$ are calculated by Eqs. (10) and (11).

$$
\beta=10^{-15} L H V_{D O} \rho_{D O}
$$




$$
e f=e f_{\mathrm{CO}_{2}}+21 e f_{\mathrm{CH}_{4}}+276 e f_{\mathrm{N}_{2} \mathrm{O}}
$$

...where $i$ is the fuel index switches to NG, DO, and $\mathrm{RO} ; j$ is the means of transport index switches to rail and road tankers; et shows emission of fuel transfer in $\mathrm{kg} ; f_{c}$ stands for fuel consumption rate of vehicles in $1 /$ ton. $\mathrm{km} ; \rho$ indicates density of fuel in $\mathrm{kg} / \mathrm{m}^{3}, L H V$ stands for low heating value in $\mathrm{kJ} / \mathrm{kg}, V$ presents volume of fuel consumed in $\mathrm{m}^{3}$, ef is emission factor in $\mathrm{kg} / \mathrm{TJ}$, and $d$ is distance of fuel transferred in $\mathrm{km}$. In Iran average diesel oil is consumed as the fuel of freight road and rail tankers. The fuel consumption of road and rail freight is, respectively, 0.0051 and $0.0361 /$ ton.km.

Fugitive emissions from oil and natural gas systems are accounted for indirectly in IPCC subcategory 1.B.2 of the energy sector [10]. The term "fugitive emissions" is broadly applied here to mean all greenhouse gas emissions from oil and gas industry systems except for contributions from fuel combustion. Oil and natural gas systems comprise all infrastructure required to produce, collect, process, or refine natural gas and petroleum products to market. The system begins at the well head, or oil and gas source, and ends at the final sales point to the consumer, where the consumer is the power plant [13]. The emission is estimated by Eq. (12):

$$
\text { ef }=\sum_{i} 10^{-6} V_{i} e f_{i}
$$

...where $i$ is the fuel index switches between $\mathrm{NG}, \mathrm{DO}$, and $\mathrm{RO} ; V$ indicates volume of fuel consumed in $\mathrm{m}^{3}$; and ef shows emission factor in $\mathrm{Gg} / 10^{6} \mathrm{~m}^{3}$.

Net electrical energy received by consumers is almost less than what is produced and this concept happens because of production and consumption location distances. However, three more elements influence the net energy produced: one related to site location, which is ambient condition, and two relevant to plant type, degradation, and own consumption. These parameters are formulated in Eqs. (13-19). The net electrical energy assumed for carbon footprint is estimated by Eq. (13):

$$
E=P^{\prime} . O H
$$

... where $P^{\prime}$ is modified power in $\mathrm{MW}$ and $\mathrm{OH}$ is operating hours. Modified power is the actual produced power estimated from the nominal power in ISO condition due to degradation, own consumption, ambient condition, transmission, and distribution. ISO condition is a standard condition for ambient condition, in which nominal power and actual power are the same. This condition is as follows: temperature $15^{\circ} \mathrm{C}$, pressure 1.013 bar, and $60 \%$ relative humidity $(\mathrm{RH})$. The aforementioned factor represents the portion of power after the reduction caused by the abovementioned parameters. Modified power is calculated by Eq. (14):

$$
P^{\prime}=P . f
$$

...where $P$ is nominal power in MW and $f$ is power factor. Power factor, which is a representative of power reduction coefficient, has five elements that are demonstrated in Eq. (15):

$$
\begin{gathered}
f=f_{\text {degradation }} f_{\text {own consumption }} \\
f_{\text {ambient condition }} f_{\text {transmission }} f_{\text {distribution }}
\end{gathered}
$$

The above cited parameters are calculated by Eqs. (1619).

$$
\begin{aligned}
f_{\text {transmission }} & =1-L_{\text {transmission }} \\
f_{\text {distribution }} & =1-L_{\text {distribution }} \\
f_{\text {own consumption }} & =1-L_{\text {own consumption }}
\end{aligned}
$$

...where $L$ stands for loss coefficients. The detailed model of the above-mentioned losses are stated within the next sections. Degradation is the power plant loss due to fouling, which is recoverable, and aging, which is non-recoverable unless parts are replaced. The simplified average non-recoverable degradation is modeled and functionalized with Eq. (19) [14].

$$
f_{\text {degradation }}=\frac{1}{a+b \operatorname{Ln}(\mathrm{OH})+c \operatorname{Ln}\left(\mathrm{OH}^{3}\right)}
$$

The coefficients are different for steam, gas, and combined cycle power plant and are presented in Table 1.

The ambient condition function is dependent upon average ambient temperature $\theta$ (in degree $\mathrm{C}$ ), the atmospheric pressure as reflected in average altitude $h$ (in $\mathrm{m}$ above sea level - a.s.l.), and the average percentage relative humidity $(R H)$. This is reflected in statement (20):

$$
f_{\text {ambient condition }}=f(h) f(\theta) f(R H)
$$

Elevation from sea level (air pressure) influences air density. Increasing the altitude reduces the density of the air and consequently reduces the air mass flow into the compressor and power output. In Iran the highest attitude on which plant establishment can be seen is 3,000 $\mathrm{m}$ a.s.l. In this order of a.s.1., the atmospheric pressure varies linearly with altitude [14]. Thus the power factor varies linearly with altitude and is represented by Eq. (21).

Table 1. Degradation coefficients.

\begin{tabular}{|c|c|c|c|}
\hline & $a$ & $b$ & $c$ \\
\hline Steam plant & 1 & -0.01 & 0.000057 \\
\hline Gas cycle plant & 0.99 & -0.00075 & 0.00002 \\
\hline Combined cycle plant & 0.96 & 0.0051 & $0.9 \mathrm{e}-6$ \\
\hline
\end{tabular}




$$
f(h)=1-0.00011(h)
$$

Average ambient temperature also has great effect on power output. Increasing the ambient temperature reduces the density of the air and consequently reduces the air mass flow into the compressor as constant volume engine. This is the main reason for changes in the gas turbine power output. Books have been published as practice for gas turbines produced power factor graph for average ambient temperature; the data fit into the Ratkowsky model. Eqs. (22) and (23) represent the effect of temperature on gas turbine and combined cycle plants, respectively:

$$
\begin{aligned}
& f(\theta)=\frac{1.798}{1+\mathrm{eq}(-0.15+0.015 \theta)} \\
& f(\theta)=1.0482 e^{-0.0032 \theta}
\end{aligned}
$$

Gas turbine and combined cycle output will increase if the relative humidity of the ambient air increases, while other conditions remain constant. This is because at higher relative humidity there will be a higher water content in the working medium of the gas cycle, resulting in a better gas turbine enthalpy drop and more exhaust gas energy entering the heat recovery steam generator (HRSG). Eq. (24) is used to quantify the effect.

$$
f(R H)=0.994+0.0045(R H)
$$

For a steam plant, ambient conditions have no influence on the produced electricity because steam plants uses a closed cycle and the working medium is water. Therefore, power factor function equals one, i.e. $\mathrm{f}_{\text {ambient condition }}=1[15]$.

Transmission and distribution result in considerable losses in national grids. According to statistics released in 2013, NG has a loss of $3.45 \%$ in transmission and $14.9 \%$ in distribution. For the purpose of reducing the complexity of the grid, specific transmission electrical loss for each voltage level is introduced and has been calculated as follows. Losses are assumed to be the function of voltage level and circuit length of each voltage level. In this regard, total loss of transmission are separated for three different voltage levels: 400, 230, and $132 \mathrm{kV}$. In the next step, the calculated loss for each voltage level has been divided into the length of its circuit. As a result, average loss for each specified voltage level per $\mathrm{km}$ is calculated. Transmission is modeled to cascade voltage reduction from $400 \mathrm{kV}$ to $132 \mathrm{kV}$. This method is also applied for the distribution loss.

Own consumption of the plant should also be subtracted from the power generated while the consumption makes the footprint larger. Own consumption has a wide range because of the variation of equipment and their manufactures. However, for each type of plant the average is almost constant. The average own consumption of a steam power plant is $7.35 \%$, a combined cycle power plant is $1.8 \%$, and a gas turbine plant is $1.85 \%$.

\section{Results and Discussion}

The derived model is verified by the three power plants in Iran's electrical network that are in semi-ISO condition for a $162 \mathrm{MW}$ gas turbine, $486 \mathrm{MW}$ combined cycle, and $325 \mathrm{MW}$ steam plant. Their carbon footprints are assessed at 561.75, 344.15, and $621.33 \mathrm{~g} \mathrm{CO}_{2}$ eq/ $\mathrm{kWh}$, respectively. For verification, the three above-mentioned power plants were assumed in ISO condition and newly born. The carbon footprint of standard condition is calculated and then each parameter effect is estimated and the total carbon footprint of the power plants is calculated.

As has already been mentioned, nine different parameters are investigated and presented here: plant and fuel type, fuel preparation emission, fuel transfer

Table 2. Specification for standard gas turbine power plant.

\begin{tabular}{|c|c|}
\hline \multicolumn{2}{|c|}{ Standard Gas Turbine Plant } \\
\hline Capacity (MW) & 162 \\
\hline Fuel Type & Natural gas \\
\hline Site ambient condition & ISO Condition \\
\hline Own consumption & $0.75 \%$ \\
\hline Age & 0 \\
\hline Operating hours & 8,760 \\
\hline Location of electricity delivered & Plant substation \\
\hline
\end{tabular}

Table 3. Specification for standard combined-cycle power plant.

\begin{tabular}{|c|c|}
\hline \multicolumn{2}{|c|}{ Standard Combined Cycle Plant } \\
\hline Capacity (MW) & 486 \\
\hline Fuel Type & Natural gas \\
\hline Site ambient condition & ISO Condition \\
\hline Own consumption & $1.85 \%$ \\
\hline Age & 0 \\
\hline Operating hours & 8,760 \\
\hline Location of electricity delivered & Plant substation \\
\hline
\end{tabular}

Table 4. Specification for standard steam power plant.

\begin{tabular}{|c|c|}
\hline \multicolumn{2}{|c|}{ Standard Combined Cycle Plant } \\
\hline Capacity (MW) & 325 \\
\hline Fuel Type & Natural gas \\
\hline Site ambient condition & ISO Condition \\
\hline Own consumption & $7.5 \%$ \\
\hline Age & 0 \\
\hline Operating hours & 8,760 \\
\hline Location of electricity delivered & Plant substation \\
\hline
\end{tabular}


emission, degradation, own consumption, site ambient condition, and transmission and distribution losses. The proposed model is used to estimate the carbon footprint of three types of power plants in ISO standard condition. The specifications for each power plant are presented in Tables 2-4.

Results show that the carbon footprint of a standard gas turbine power plant is $496.25 \mathrm{~g} \mathrm{CO}_{2} \mathrm{eq} / \mathrm{kWh}$. This amount varies to $289.3 \mathrm{~g} \mathrm{CO}_{2} \mathrm{eq} / \mathrm{kWh}$ for combined cycle and $505.4 \mathrm{~g} \mathrm{CO}_{2} \mathrm{eq} / \mathrm{kWh}$ for a standard steam power plant. The mentioned carbon footprints are the carbon footprint of plant operation without considering up- and downstream emissions without own consumption and degradation effect. After considering the effect of up and down steam emissions - including fuel preparation and transmission, electricity transmission and distribution, and ambient condition - without considering degradation and own consumption of the plants, their carbon footprint increases to 550,342 , and $600 \mathrm{~g} \mathrm{CO}$ eq/ $\mathrm{kWh}$. To verify the three models, existing plants with the same capacity were chosen from Iran's electrical grid. The carbon footprints are mentioned in the previous section. The real carbon footprint of the existing plants is $561.75,344.15$, and $621.33 \mathrm{~g} \mathrm{CO}_{2} \mathrm{eq} / \mathrm{kWh}$. The calculated error is less than $5 \%$. Thus the proposed model is compatible with existing conditions and can be applied worldwide.

While considering the age of a real existing plant (20 years for steam plant, 11.5 years for gas turbine, and 7 years for combined cycles), the own consumption and final carbon footprint increases to 589.6, 355.8, and $681.3550 \mathrm{~g} \mathrm{CO}_{2}$ eq/ kWh.

Results show that the up- and downstream emissions can increase the carbon footprint of a unit product by $60 \%$. This happens like a domino for industries related to each other. For example, when the carbon footprints of fuel stream extraction, processing, and transmission increase or decrease, the carbon footprint of electricity produced also changes.

\section{Conclusions}

From Eq. (1) it is obvious that the best trend from a mathematical point of view is to decrease the numerator and increase the denominator, which means decreasing the emissions and increasing the total product within one specified timespan. For each plant type (GT, CC, ST), the influence of each element is investigated. The first clear vision belongs to combined cycle power plants, which have the lowest carbon footprint in an equal condition with other kinds of plants. Combined cycle plants possess a high working coefficient of the plant (almost the same as steam plants), which make them a good choice to conserve the stability of the network. The only limitation for a combined cycle power plant worldwide is the fuel choice. Although combined cycles cannot consume coal without coal gasification, from the global warming perspective a limitation to coal consumption is highly acceptable. Fuels are also a key parameter for reducing the carbon footprint of electricity. Natural gas, diesel oil, residual oil, and coal are in order from least to most carbon footprint without any carbon capture and storage devices. Different types of fuel cause different emissions of fuel extraction and processing, namely fuel preparation.

When fuel is prepared, its transmission is also a cause of increasing the carbon footprint. The best choice of fuel transfer is pipelines, railways, and then roads. In Iran the three choices are used depending on the location of the plant. Natural gas is delivered via pipelines, liquid fuels are the options of change. The Shazand and Sahand power plant receives liquid fuels by pipeline, while Genaveh power plant receives it via road trucks. Developing the railway freight network can help to reduce the carbon footprint of the plants.

The following elements influence the electrical energy that is delivered to end users. The first evaluated parameter is own consumption, which depends on the technology of the devices in the plant (basically electromotor) and also depends on the plant types and fuel types, lighting, and climate of the region for space heating, cooling, and ventilation. Using a building and lighting management system, passive heating cooling, a variable frequency electromotor, and efficient heat and steam tracing can reduce the consumption of the plant to as low a figure as possible. Degradation is the next parameter. Compatibility of technology and fuel type, regular operation, and maintenance schedules and overhaul schedules and part replacement can slow the pace of degradation. The next parameter is site ambient condition. Site ambient with the factors of average atmospheric pressure, average ambient temperature, and relative humidity can cause a variation of $50 \%$ in carbon footprint of the plant. Investigation shows that steam plants have the least sensitivity to ambient condition, which is neglected in literature. Combined cycles stand are next. Gas turbines in the last place are the technology most sensitive to ambient conditions. This parameter should be predicted in the feasibility study phase of the plant, after which construction is not controllable.

The last parameter is transmission and distribution losses, which can cause $20 \%$ variation of carbon footprint of the energy delivered to the final consumer. Transmission losses can be reduced by constructing a power plant near the place of consumption. However, distribution of low-medium to low-voltage energy in the place of consumption is reduced only by the renovation of transformers and cables. Studies of sustainable networks show that the future direction is toward a smart grid with smart regulation instead of a conventional grid. The development of smart grids is essential if the global community is to achieve shared goals for energy security, economic development, and climate change mitigation.

\section{References}

1. International Energy Agency, $\mathrm{CO}_{2}$ Emissions from Fuel Combustion HIGHLIGHTS, International energy agency, 2014. 
2. BRIZMOHUN R., RAMJEAWON T., AZAPAGIC A. Life cycle assessment of electricity generation on Mauritius. Journal of Cleaner Production, 106, 565, 2015.

3. TREYER K., BAUER C. The environmental footprint of UAE's electricity sector: combining life cycle assessment and scenario modeling. Renewable and sustainable energy review, 55, 1234, 2016.

4. VISKOVIC A., FRANKI V. Status of Croatia's energy sector framework: progress, potential, challenges and recommendations. Thermal Science. 19, 751, 2015.

5. ATILGAN B., AZAPAGIC A. An integrated life cycle sustainability assessment of electricity generation in turkey. Energy Policy. 93, 168, 2016.

6. GEORGAKELLOS A.D. Climate change external cost appraisal of electricity generation systems from a life cycle perspective: the case of Greece. Journal of Cleaner production. 32, 124, 2012.

7. BOZIC V., CVETKOIC S., ZIVKOVIC B. Influence of renewable energy sources on climate change mitigation in Serbia. Thermal Science. 19, 411, 2014.

8. ISO, Greenhouse gases - Carbon footprint of products - Requirements and guidelines for quantification and communication. International Organization for Standardisation, Geneva, Switzerland. 2013.
9. IPCC, Climate Change: Mitigation. Contribution of Working Group III to the Fifth Assessment Report of the Intergovernmental Panel on Climate Change. Cambridge University Press, Cambridge. United Kingdom and NewYork, NY, USA. 2014.

10. IPCC, IPCC Guidelines for National Greenhouse Gas Inventories. IGES, Japan, Tokyo, 2006.

11. LI F. A Cost Analysis of Carbon Dioxide Emission Reduction Strategies for New Plants in Michigan's Electric Power Sector. PhD thesis, Michigan Technology University. Michigan, USA, 2014,

12. WIĘK A., TKACZ T. Carbon Footprint: an Ecological Indicator in Food Production. Pol. J. Environ. Stud. 22, 53, 2013.

13. RAJ R., GHANDEHARIUN S., KUMAR A., LINWEI M. A well to wire life cycle assessment of Canadian shale gas for electricity generation in China. Energy. 111, 642, 2016.

14. KEHLHOFER R., HANNEMANN F., STIRNIMANN F., RUKES B. Gas and steam turbine power plants, PennWell, Oklahama, 2009.

15. Iran Parliament, http://rc.majlis.ir/fa/news/show/883581 